\title{
The influence of animacy on the choice of referring expressions in German
}

\author{
Miriam Ellert, Heinke Jank, Anke Holler \\ Courant Research Centre "Text Structures", University of Göttingen, Germany \\ https://doi.org/10.36505/ExLing-2012/05/0012/000218
}

\begin{abstract}
In this article, we present the results of a written sentence completion task in German which investigated the influence of antecedent animacy and position on the choice of referential expression. Such an effect has been shown for English (Fukumura \& Gompel 2011). However, in contrast to English where speakers in these contexts generally chose to realize reference via full NPs or personal pronouns, in German speakers may also apply demonstrative pronouns (Ellert \& Holler 2011). Thus, the current study asked whether this cross-linguistic difference would also lead to differences in reference realizations.
\end{abstract}

Key words: anaphora, animacy, sentence completion task, psycholinguistics

\section{Phenomenon}

Referring to a previously mentioned entity in discourse may be realized with different referential forms: lexical NPs, proper names, and pronouns. Languages differ in the means they have at disposal; e.g. whether they make use of pronominal clitics, or whether they overtly or covertly realize pronominal reference. However, it is assumed that the choice of referring expressions is determined by a universal principle: fuller referential forms (such as NPs) refer to less salient entities while less fuller forms (such as pronouns) refer to more salient entities (Ariel 1990; Ariel 2001; Givón 1983; Gundel et al. 1993). A vast body of research has addressed the question what exactly determines the salience level of an antecedent, and has identified several factors, such as e.g. the order of mention of the antecedent candidates (Gernsbacher \& Hargreaves 1988; Gernsbacher et al. 1989), their grammatical functions (Crawley et al. 1990; Frederiksen 1981) and their level of animacy (Ellert \& Holler 2011). Moreover, it has been shown that different referential forms (such as personal pronouns and demonstrative pronouns) may be influenced to a different degree by these factors (Kaiser \& Trueswell 2008). This leads to the question whether this difference may also be observed between languages, even more so when languages differ with regard to the referential means they provide to realize referential relations.

An interesting case is the comparison of usage of demonstrative pronouns in German and English. While demonstrative pronouns are quite frequently used in German to make reference to previously mentioned entites (1) (see corpus study by Ahrenholz 2007), in English they may not be used in the same contexts (2). Thus, it may be asked whether

ExLing 2012: Proceedings of 5th Tutorial and Research Workshop on Experimental Linguistics, 27-29 August 2012, Athens, Greece 
these pronominal differences between languages may also lead to a different degree of sensitivity towards factors marking salience, such as the animacy level of the antecedents or their position in the sentence.

(1) Die Hooligans haben den Beschluss ziemlich manipuliert.

...Der Beschluss $\mathrm{NP}_{\mathrm{N}} / \mathrm{Er}_{\mathrm{pers}} /$ Der $_{\mathrm{dem} / \text { Dieser }_{\mathrm{dem}}}$ führte $\mathrm{zu}$ einer großen Diskussion.

(2) The hooligans influenced the decision quite clearly.

$\ldots$...The decision ${ }_{\mathrm{NP}} / \mathrm{it}_{\mathrm{pers}}$ led to a huge debate.

The current study addressed this issue by replicating an English sentence completion study (Fukumura \& Gompel 2011) which asked whether the animacy level of the antecedent (animate, inanimate) had an effect on the choice for a referential form. The English study showed that participants used more pronouns (such as it) than full NPs (such as the decision) for animate than for inanimate referents. This was found for NP1-reference as well as NP2-reference, however, in the latter case less pronouns were used.

In German, Ellert \& Holler (2011) conducted a visual-world eyetracking task and found that personal pronouns were preferentially resolved towards first-mentioned animate antecedents. However, they also tested the resolution of demonstrative pronominal forms and found that they were not affected by the animacy level of the antecedents, showing a robust preference towards NP2. Thus, these results hint at cross-linguistic differences: while it may be quite common for German speakers to refer to NP2 via a demonstrative pronominal form, English speakers may rather use full NPs since demonstrative pronouns are not licensed in these contexts.

\section{Method}

The current study addressed these issues by adapting the English sentence completion task by Fukumura and Van Gompel (2011) to German using a within-subject design. Twenty-four experimental items were created which presented a first antecedent sentence in SVO word order either showing two definite animate NPs (AA), two inanimate NPs (II), or two NPs of mixed animacy levels (AI, IA). One of the NPs was underlined as in (1) and participants were asked to fill in a second sentence referring to the underlined NP which in half of the cases appeared as the grammatical subject and in the other half as the object of the sentence. The sentences were never ambiguous in that the underlined entity was a singular NP and the other a plural NP. Thus the factors syntactic role (subject, object), animacy condition (animate, inanimate) and competitor animacy (same, different) gave rise to a $2 \times 2 \times 2$ design, resulting in eight conditions for each item. The items were distributed across eight experimental lists following a 
latin square design, and fourty-eight filler items were added to the lists. Each participant saw each item only once and the order of presentation was randomized for each participant.

\section{Results and discussion}

The results ${ }^{1}$ showed that participants indeed had a clear preference to use more pronominal forms over all conditions $(86 \%)$. Personal pronouns were the preferred form in all conditions, but they were less preferred for NP2reference (68\% vs. $87 \%$ for NP1-reference). This is comparable to the results of the previous sentence completion study by Fukumura and Van Gompel (2011) in English. However, differentiating between the two types of pronouns used, demonstrative pronouns patterned more like full NPs in that they were used more often when referring to the object antecedent (both around $15 \%$ ) than to the subject supporting the view that there exists a crosslinguistic difference.

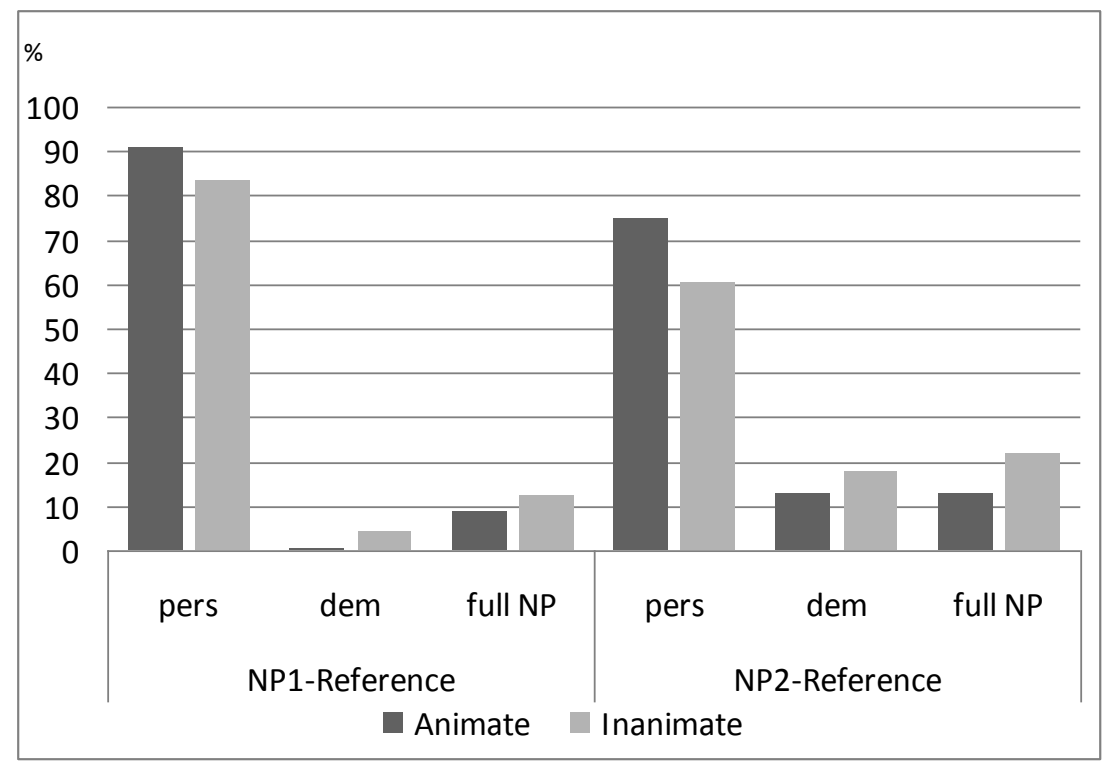

Figure 1. Distribution of the types of referential expressions used as a function of position and animacy of the antecedent

Target animacy affected the results in that personal pronouns were more frequently used with animate antecedents than inanimates, while demonstrative pronouns and NPs were more frequently used to refer to inanimate than animate antecedents. Competitor animacy had no effect. Since the use of demonstrative pronouns was in general quite low compared to personal pronouns, it may be asked whether presenting the materials in 
spoken language (as in Ellert \& Holler, 2011) would increase their use. Therefore, the experiment is currently replicated in spoken German in order to investigate whether there are any changes in preferences across modalities.

\section{Notes}

1. We conducted a loglinear analysis on the data which showed that the three-way interaction choice $x$ syntactic role $x$ target animacy and its main effects significantly well predicted the data. To break down the effects separate chisquare tests were conducted. Due to space limitations, we restrain ourselves to report the statistically significant results. The interested reader is very much welcome to contact the corresponding author for the exact values (mellert@unigoettingen.de).

\section{References}

Ahrenholz, B. 2007. Verweise mit Demonstrativa Im Gesprochenen Deutsch. Grammatik, Zweitspracherwerb und Deutsch als Fremdsprache. Berlin and New York: Walter De Gruyter Inc.

Ariel, M. 1990. Accessing NP antecedents London: Routledge.

Ariel, M. 2001. Accessibility theory: an overview. Text representation, linguistic and psycholinguistic aspects, ed. by T. Sanders, J. Schilperoord \& W. Spooren, 29-87. Amsterdam/ Philadelphia: John Benjamins.

Crawley, R., Stevenson, R., \& Kleinman, D. 1990. The use of heuristic strategies in the interpretation of pronouns. Journal of Psycholinguistic Research 4, 245-64.

Ellert, M., \& Holler, A. 2011. Semantic and Structural Constraints on the Resolution of Ambiguous Personal Pronouns - A Psycholinguistic Study, ed. by Hendrickx, 157-70. Berlin, Heidelberg: Springer.

Frederiksen, J. 1981. Understanding anaphora: Rules used by readers in assigning pronominal referents. Discourse Processes 4, 323-47.

Fukumura, K., \& Van Gompel, R. P. G. 2011. The effect of animacy on the choice of referring expression. Language and Cognitive Processes 26, 1472-504.

Gernsbacher, M. A., \& Hargreaves, D. J. 1988. Accessing sentence participants: The advantage of first mention. Journal of Memory and Language 27, 699-717.

Gernsbacher, M. A., Hargreaves, D. J., \& Beeman, M. 1989. Building and accessing clausal representations: The advantage of first mention versus the advantage of clause recency. Journal of Memory and Language 28, 735-55.

Givón, T. 1983. Topic continuity in discourse: A quantitative cross-language study Philadelphia/ Amsterdam: John Benjamins.

Gundel, J. K., Hedberg, N., \& Zacharski, R. 1993. Cognitive status and the form of referring expressions in discourse. Language and Cognitive Processes 69, 274307.

Kaiser, E., \& Trueswell, J. 2008. Interpreting pronouns and demonstratives in Finnish: Evidence for a form-specific approach to reference resolution. Language and Cognitive Processes 23, 709-48. 